\title{
The Use of Seed Vigour Tests for Predicting Field Emergence
}

\section{In Acacia Senegal and Acacia Mellifera}

\author{
Fatima A. Hassan ${ }^{1} \&$ Mai M. A. Hassan ${ }^{2}$ \\ ${ }^{1}$ Department of Forestry and Range Sciences, Faculty of Agriculture and Natural Resources, White Nile State \\ (AD Duwem), Sudan \\ ${ }^{2}$ National Tree Seed Centre, Forest Research Centre, Agricultural Research Cooperation, Ministry of Agriculture, \\ Khartoum, P.O. Box: 7089, Khartoum, Sudan \\ Correspondence: Fatima Algunaid Hassan, Associate Prof. of Plant and Environment Sciences, Department of \\ Forestry and Range Sciences, Faculty of Agriculture and Natural Resources, White Nile State (AD Duwem), Sudan. \\ Tel: 249-911-633-434.
}

Received: October 14, 2018; Accepted: October 29, 2018; Published: December 19, 2018

\begin{abstract}
The general aim of this study was to address the problem of seed vigour testing in Acacia senegal and Acacia mellifera) by studying different seed vigour tests and comparing them to identify the most suitable test for each species. The importance of this study lies in the fact that vigour testing measures the percentage of viable seeds in a sample as well as their ability to produce normal seedlings under less than optimum or adverse growing conditions, similar to those occurring in the field. To achieve this objective, a set of laboratory and field tests were conducted for the two Acacia species. Data collected included: The number of seeds per kilogram, germination percentage, seedling shoot length, seedling root length, seedling root wet and dry weight, seedling shoot wet and dry weight. The cutting test, electrical conductivity tetrazolium test and Hiltner test were employed to determine the seed vigour.

The results showed that Acacia mellifera had a high electrical conductivity, indicating its low seed vigour. The electrical conductivity of Acacia senegal was equivalent to that of distilled water, indicating that either the seed coat was intact or no ions were leached from the seeds. Comparison of the various tests suggests that Hiltner test is the most accurate" or "reliable") test for seed vigor.
\end{abstract}

Keywords: seed, vigour test, seedling growth rate, standard germination test, Acacia

\section{Introduction}

Acacia is a genus of the subfamily Mimosoideae (Rehman et al., 1999) that occurs across a wide range of ecosystems, from arid deserts to montane forests, with growth forms that include small shrubs, lianas and large trees (New, 1984). Acacia grow relatively quickly and are a source of nitrogen in the forest ecosystems. Many species of Acacia have considerable value as emergency fodder and play a significant role as browse plants in dry zones. The wood is useful for fuel, fence posts and poles, while the trees provide shade and shelter (Nasr et al., 2013) and are essential for soil conservation. Moreover, Acacia produces Gum Arabic, which is the most economically important product of all acacia (Aref, 2000). There has been an increase in private and community forest plantations to promote these desirable products and services (Abdel Magid, 2006). Attempts have been made to choose species that can be used for a wide range of purposes and endure under prevailing unfavorable environmental conditions, such as drought, salinity and infertile soils. However, the success of any planting depends on the seed quality, planting techniques, and knowledge of the appropriate species to be planted as well as the amount of seeds required for planting (AOSA, 2008). Seed vigour is the key element for seed quality. Seeds selected based on high vigour produce uniform, vigorous stands of plants, resulting in higher yields per unit area (Tomer and Maguire, 1990). Many vigour tests have been developed for the rapid estimation of seed vigour in seed programs. There are no suggested or recommended procedures in the handbooks of vigour tests from the International Seed Testing Association (ISTA, 1995) or Association of Official Seed Analysts (ISTA, 1995) for conducting seed vigour tests in Acacia species. Since Acacia species are valuable trees in Sudan; it is essential to have proper vigour tests to evaluate the seeds of Acacia and thus improve seed quality, which would enhance its 
productivity and benefit farmers. So the objective of this study was to compare different vigour tests with the field test to identify the most suitable test for each species.

\section{Materials and Methods}

The seeds used in this study were obtained from the National Tree Seed Centre- Soba, Khartoum, Sudan, and were collected from different locations at different times. To evaluate the seed vigour many tests were conducted such as cutting test as described by Willan, 1985).Standard germination test (SG), seedling root length (RL), seedling growth rate test (SGR), tetrazolium test, electrical conductivity test (EC), field emergence test (FE) and Hiltner test (AOSA. 2009).

For Standard germination test (SGT) Three replications of 100 seeds were drawn from each seed species. The seeds were sown in round aluminum dishes filled with moist sand. The dishes were watered daily with a fine shower using tap water (Elias, S. G., and L. O. Copeland, 1997). Germination was carried out in a controlled germination room 30c; light was provided for 12 hours by fluorescent lamps. Germination counts were conducted at 7 day intervals for 4 weeks. A seed was considered to be germinated when the radical emerged $2 \mathrm{~mm}$ in length (Pirasteh-Anosheh et al., 2011). In each recording, ten seedlings were randomly selected from each aluminum dish, and their averages were considered to be the sample data. The measured traits included the radicle and shoot lengths, radicle to shoot length ratio, radicle and shoot weights, (Soman and Peacock, 1985) and vigour test results(ISTA, 1995) \& (ISTA, 1995).

The root length (RL) and shoot length(SL) of the normal seedling was measured as described by Tennant (1975). For the Tetrazolium test, four replications of 100 seeds were used for each treatment to activate the respiration enzymes. The seeds were longitudinally cross-sectioned through the embryo and placed in a TZ solution (0.1$1.0 \%$ ) for a period of time as indicated in the AOSA TZ Handbook. Two halves of the seeds were placed in the dark for 3 days with a $0.1 \%$ Tetrazolium salt solution. The seeds were removed from the chamber and washed with tap water. Seed viability was evaluated, and their structures were observed visually; the seeds were classified according to the degree of coloration of each species separately (dark pink, pale pink, and white).

For Conductivity test (CT) Three replications of 100 uninjured seeds from each species were weighed to 2 decimal places. The seeds from each replication were placed in a $250-\mathrm{ml}$ beaker, and $250 \mathrm{ml}$ of distilled water was added. The electrical conductivity of the leachates of each replication was measured using a conductivity meter, and the conductivity per gram of seed weight was calculated $\left(\mu \mathrm{S} \mathrm{cm}^{-1} \mathrm{~g}-{ }^{-1}\right)$ and recorded.

For Hiltner test four replicates of 25 seeds per species were placed on $2 \mathrm{~cm}$ of tamped moist coarse sand (particle size $>2 \mathrm{~mm})$ in plastic dishes and then covered with $3 \mathrm{~cm}$ of small bricks $(>5 \mathrm{~mm})$. The test was performed in a controlled germination room and repeated in the field. The numbers of normal and abnormal seedlings were counted weekly

Field emergence test (FE) was conducted To evaluate the ability of the seedlings to survive under harsh conditions, three replications of 100 seeds were planted in sandy clay soil. The seeds were hand planted. The plots were watered immediately after planting and every day thereafter. The normal and abnormal seedlings we counted on a daily basis after sowing.

Statistical analysis was performed by the JMP package (Programme improved from SAS Package) (SAS Institute Inc. 1989); The means were compared using a Tukey- Kramer test.

\section{Results and Disscusion}

\subsection{Cutting Test}

The simplest viability testing method is the direct visual inspection of seeds that have been cut open with a knife or a scalpel. It is useful tool for estimating the size and maturity of the seed crop before collection and the efficiency of the methods used in its processing. It is a valuable test for determining the existence of empty seeds and seeds with significant insect infestation. As Acacia Senegal had $82 \%$ sound seeds and Acacia mellifera had $88 \%$, they were predicted to reach this percentage when these seeds w sown (Figure 1). The germination percentage did not vary between the sound seed percentage and the germination percentage in both germination room and field for the two species Acacia mellifera and Acacia senegal (Table 5). These results were in agreement with Willan (1985), who found a good correlation between cutting and germination tests in fairly large-seeded species, such as Leucaena, intsiabijuga and Lagerstroemia species, but the germination percentage that was found was consistently $10-20 \%$ less than the percentage of sound seeds on the cutting test. More experiments are needed to draw a stronger correlation between the two. Although Acacia mellifera seeds were new when collected, the percentage of the sound seeds was low. The low yield could be due to weather conditions during maturation, which significantly affects the seed quality. Moderate temperature, moisture, and sunshine promote the growth of large, viable kernels 
that are excellent seeds for establishing the next season's crop. The weather conditions are sometimes unfavourable during maturation of the seed crop and affect the seed quality directly and indirectly. Indirect effects, such as high humidity, which favours the development of disease-causing organisms, are well known and have been studied in considerable detail. The direct effects of weather are less well-known, but can lower seed quality considerably (Matthews, 1985; Basavarajappaetal, 1991; Das, Sen-Mandi \& McDonald, 1999).

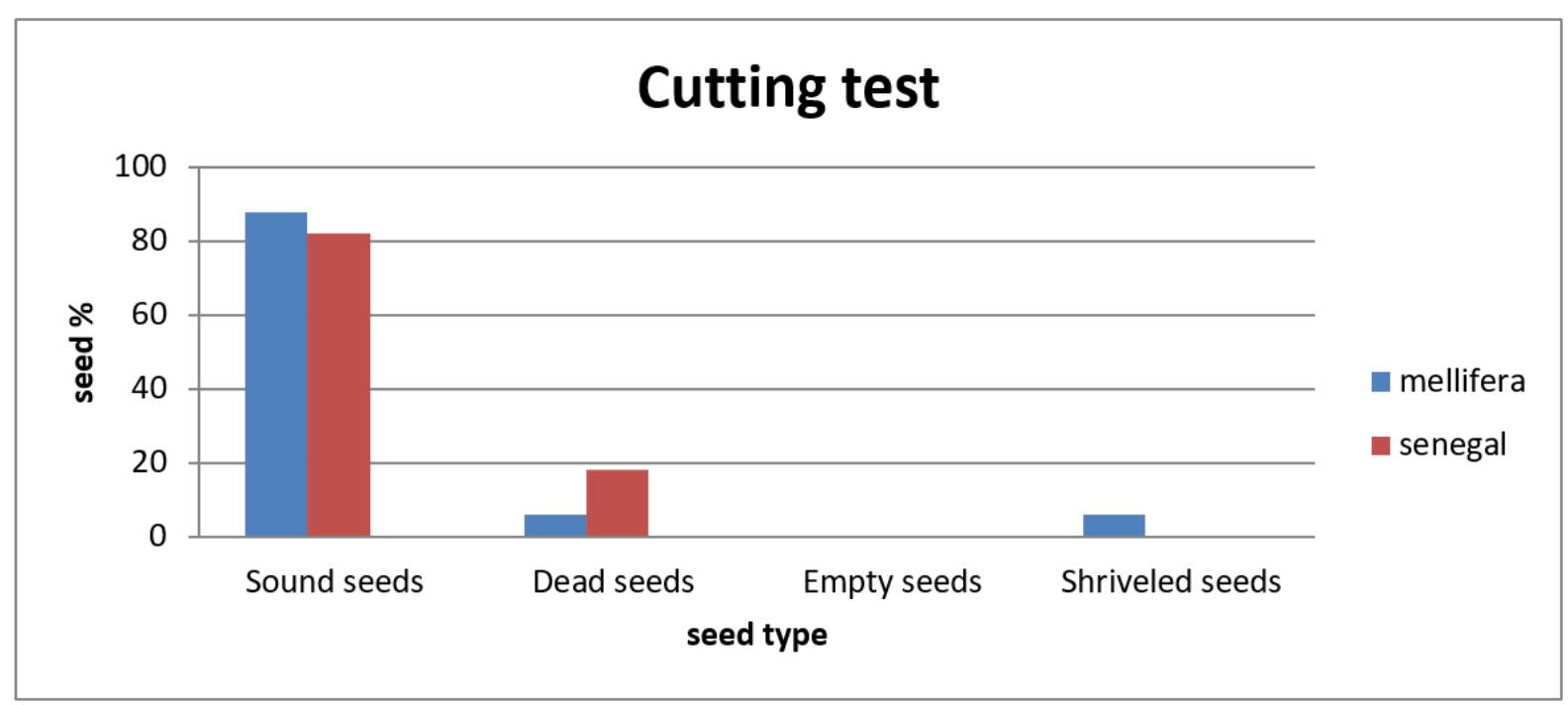

Figure 1. Percentage of viable seeds with using Cutting teston Acacia senegal \& Acacia mellifera seeds

\subsection{Electrical Conductivity}

This electrical conductivity test measures the integrity of cell membranes, which is correlated with seed vigour. As seeds lose vigour, nutrients exude from their membranes, and thus, low-quality seeds leak electrolytes, such as amino acids and organic acids, while high-quality seeds retain their nutrients within well-structured membranes. Therefore, seeds with higher conductivity measurements are low-quality seeds, and vice versa. Seeds with high electrolyte leakage show poor field establishment (Taylor, 1995; Perry, 1980). Higher vigour seeds can reorganize their membranes more rapidly, and electrolyte leakage measured from these seeds is less than that measured from low vigour seeds with a high conductivity of seed leachate. The EC value of A. mellifera was 35.83 and for $A$. senegal was 1 (Table 1). One is equivalent to distilled water, which means that there was no leachate from the seeds. These results should produce a high percentage of germination; however, a low germination percentage was observed (44.6 in Germination and 32.7 in the field). This can be attributed to the dormancy breaking pretreatments, for example, treatment of $A$. senegal seeds with sulfuric acid may damage the seeds. Zubairu (2014) recorded that when the seeds of $A$. senegal were treated with sulfuric acid, they showed the highest germination percentage $(50 \%)$ among different dormancy pre-treatments. Each species requires considerable study to determine the equivalent germination percentage. This study could provide a platform for similar studies in the future.

Table 1. The Electric conductivity of Acacia seeds

\begin{tabular}{lll}
\hline Species & $\mathrm{EC} / \mu \mathrm{S} \mathrm{cm}-{ }^{-1}{ }_{-}{ }^{1}$ & Temperature/co \\
\hline Acacia mellifera & 35.8 & 25.7 \\
Acacia senegal & 1.00 & 25.7 \\
\hline
\end{tabular}

\subsection{Tetrazolium Test}

The tetrazolium test aims to determine the seed tissues that are alive and have the potential to germinate under optimum conditions. Tetrazolium is a colourless chemical that reacts with living cells and stains them red. Thus, living tissue in seed embryos can be distinguished from non-living tissues. It also detects which tissues are alive or viable. Because of this, occasionally, the results from a tetrazolium test and germination test may not be comparable. This is because any factor that affects the seed during the germination process is not detected by tetrazolium tests, such as chemical damage, dormancy, and disease. In this experiment, (Table 3) and (Figures 2) 
A. senegal showed a lower germination percentage compared with A.mellifera. This may be because the degree of color intensity was estimated visually and human error should be discounted. Handbooks, such as the Munsell Plant Tissue Color Charts, that provide the classification of different degrees of colors for plant tissues were not available.

Table 2. Percentage of seed vigor of the Acacia species seeds using Tetrazolium test

\begin{tabular}{lll}
\hline Species & Colour & percentage \% \\
\hline Acacia mellifera & Dark pink & 81 \\
& Pale pink & 13 \\
& White & 6 \\
\hline Acacia senegal & Dark pink & 81 \\
& Pale pink & 16 \\
& White & 3 \\
\hline
\end{tabular}
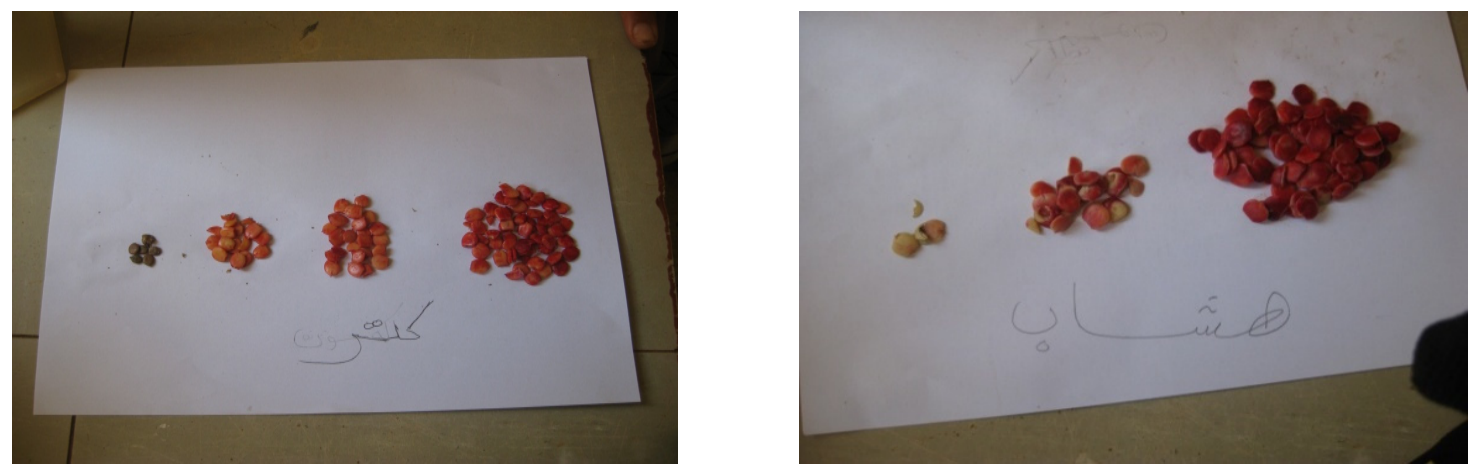

Figure 2. Comparison of the different coloron AcaciamelliferaAcacia senegal seeds respectively using the Tetrazolium

\section{Hiltner Test or Bricks Test}

Seeds infected by pathogenic fungi, injured seeds, or those low in vigour are often weak and unable to withstand adverse conditions during germination and field emergence. The brick grit layer used in the Hiltner test imposes a physical stress on the seeds. The seedlings that normally emerge through brick grit are considered to have withstood the physical stresses involved, and thus, the test provides a method for screening seed lots for vigour(ISTA 1995). Perry (1980) found this method to be reproducible and associated it with field emergence in the case of wheat

For the two species, subjected to brick stress germination percentage was not different from the germination percentage(in germination room), which provided a method that could be applied with a time limitation of one week (Tables 3,4). There was a decrease in the germination percentage in the field (Table 3and 4).

Table 3. The percentage of Acacia species seed germination using the Bricks test

\begin{tabular}{|c|c|c|c|c|c|c|}
\hline \multirow{2}{*}{ Spp. } & \multirow[t]{2}{*}{ Seedling condition } & \multicolumn{2}{|l|}{ Germination $\%$} & \multirow[t]{2}{*}{$\bar{P}$} & \multirow[t]{2}{*}{ SE } & \multirow[t]{2}{*}{ C.V. } \\
\hline & & Germination Room & Field & & & \\
\hline \multirow[t]{2}{*}{ A.senegal } & Norm & $44.6 \mathrm{a}$ & $32.7 \mathrm{a}$ & 0.163 & 8.3 & 45 \\
\hline & Abnormal & $2.9 \mathrm{a}$ & $2.9 \mathrm{a}$ & 1.000 & 3 & 106 \\
\hline \multirow[t]{2}{*}{ A.mellifera } & Norn & 62.8 & $56.6 \mathrm{a}$ & 0.409 & 4 & 16 \\
\hline & Abnormal & $6.97 \mathrm{a}$ & $8.20 \mathrm{a}$ & 0.852 & 4 & 108 \\
\hline
\end{tabular}

\section{Germination Tests}

The process of seed germination is complex and can be affected at different stages by many factors and interactions of factors, such as temperature, water availability, oxygen, light, substrate, maturity of the seed, and physiological age of the seed. In laboratory germination tests, these factors are optimized to measure the maximum number of 
seeds that are capable of producing healthy well-developed seedlings. The differences between the germination percentages in the laborites and field were highly significant for $A$ senegal. For A. mellifera the opposite was true, the seedlings in the field were more elongated than those grown in the germination room (Tables $5 \& 6$ ). This pattern of root length can be only attributed to thorny trees, which show elongated roots so that they can reach the water table in dry regions.

Baskin et al. (1993) studied the relationship between the standard germination test and the field emergence of sorghum under favorable and unfavorable field conditions. Under unfavorable field conditions (cold, wet soil condition), the mean field emergence percentage decreased between the standard germination test and field emergence. Similarly, in cotton, Bishnoi and Delouche (1980) observed no significant correlation between standard germination and field emergence. The objectives of the standard germination test and vigor tests were different. The standard germination test is universally accepted and used as a seed vigor test.

Germinating Acacia senegal seeds in the field tended to elongate the roots (Table 4). This may be a survival strategy for the seeds of plants growing in dry zones. The germination percentage obtained from the germination room or field were not significantly different (Table 4).

Table 4. Performance of Acacia species seedlings in the germination room and field

\begin{tabular}{|c|c|c|c|c|c|c|}
\hline \multirow[t]{2}{*}{ Spp. } & \multirow[t]{2}{*}{ Seedling condition } & \multicolumn{2}{|l|}{ Length $/ \mathrm{cm}$} & \multirow[t]{2}{*}{$\mathrm{P}$} & \multirow[t]{2}{*}{ SE } & \multirow{2}{*}{ C.V. } \\
\hline & & Germination Room & Field & & & \\
\hline \multirow[t]{2}{*}{ A.senegal } & Root length & $60.6 \mathrm{a}$ & $45.6 \mathrm{a}$ & 0.8 & 6 & 16 \\
\hline & Shoot length & $59.3 \mathrm{a}$ & $66.8 \mathrm{a}$ & 0.3 & 0.003 & 31 \\
\hline \multirow[t]{2}{*}{ A.mellifera } & Root length & $2.51 \mathrm{a}$ & $9.12 \mathrm{~b}$ & 0.0001 & 0.7 & 65 \\
\hline & Shoot length & $7.13 \mathrm{a}$ & $9.77 \mathrm{a}$ & 0.11 & 1.1 & 33 \\
\hline
\end{tabular}

Table 5. Comparison of the seedling root and shoot wet and dry weights in the germination room and the field in Acacia species

\begin{tabular}{lllllll}
\hline Spp. & Root Shoot Wt. & Germination\% & & & SE & C.V. \\
\cline { 3 - 4 } A.senegal & & & & \\
\cline { 3 - 4 } & Reot Wet Wt. & $0.09 \mathrm{a}$ & $0.06 \mathrm{a}$ & 0.17 & 0.01 & 40 \\
& Root Dry Wt. & $0.027 \mathrm{a}$ & $0.027 \mathrm{a}$ & 0.99 & 0.0009 & 83 \\
\hline \multirow{4}{*}{ A.mellifera } & ShellWet Wt. & $1.08 \mathrm{a}$ & $0.8 \mathrm{~b}$ & 0.007 & 0.04 & 17 \\
& Shell Dry Wt. & $0.15 \mathrm{~b}$ & $0.28 \mathrm{a}$ & 0.0003 & 0.02 & 37 \\
& Root Wet Wt. & $/$ & $/$ & $/$ & $/$ & $/$ \\
& RootDry Wt. & $0.009 \mathrm{a}$ & $0.069 \mathrm{~b}$ & 0.0001 & 0.004 & 83 \\
& Shell Wet Wt. & $0.38 \mathrm{a}$ & $0.71 \mathrm{~b}$ & 0.008 & 0.06 & 42 \\
& Shell Dry Wt. & $0.033 \mathrm{a}$ & $0.027 \mathrm{~b}$ & 0.0001 & 0.01 & 85 \\
\hline
\end{tabular}

Germination percentage in the germination room was not significantly different from the germination percentage in the field, so this test can be used as a vigor test for Acacia mellifera seeds. Moreover, the Hiltner test in the field and the dark pink colored tetrazolium test can also be used as vigor tests. While the vigor test can be conducted easily in most seed testing laboratories with minimum expenditure for equipment and training of personnel

In this research the Hiltner's test predicted the field emergence of seeds of $A$ cacia species and was used to test seed vigor. The Hiltner's test takes less time than the other germination tests.

The conductivity test offers quick (24 hrs) results but Physically injured and mechanically damaged seeds can influence the results (AOSA, 1983) because the loss of membrane integrity and electrolyte leakage are the first symptoms of seed deterioration (McDonald 1999). Thus, the measurement of electrolytes or the conductivity test should be the most important and effective seed vigour tests as they can differentiate between high and low vigour seeds at a very early seed deterioration stage. The conductivity test of A.senegal in our study was conducted for the first time in these species and the results can be compared with those in future studies. This result may also pave the way for studies on the lifespan of Sudanese trees and their deterioration during seed storage. 


\section{Conclusion and Recommendation}

\subsection{Conclusions}

- The appropriate seeds vigour test depends on the tree species as it varies from one species to another. This may be due to the nature of dormancy.

- The cutting test is not an accurate test in Acacia species for testing seed germination.

\subsection{Recommendations}

- Studies on the life span of Sudanese trees and the deterioration that occurs during seed storage should be conducted.

- Future research should be conducted on the suitability of the conductivity test to predict the storage potential of the $A$ cacia seeds.

\section{References}

Abdel Magid, T. D. (2006). Potential of irrigated forest plantations in the Sudan. Conference, Nile Basin Development Forum.

AOSA. (1983). Seed Vigor Testing Handbook. Contribution No. 32. Association of Official Seed Analysts. Lincoln, NE., USA.

AOSA. (2008). Cultivar Purity Testing Handbook. Assoc. Off. Seed Anal. Ithaca. NY. Applied Ecology, 16, 641647.

Aref, I. M. (2000). Morphological characteristics of seeds and seedling growth of some native acacia trees in Saudi Arabia. Journal of King Saud University, Agricultural Sciences, 12(2), 31-95.

Basavarajappa, B. S., Shetty, H. S., \& Prakash, H. S. (1991). Membrane deterioration and other biochemical changes, associated with accelerated ageing of maize seeds.

Baskin, C. C., Paliwal, S., \& Delouch, J. C. (1993). Estimating Field Emergence of Grain Sorghum.

Bishnoi, U. R., \& Delouche, J. C. (1980). Relationship of vigor tests and seed lots to cotton seedling establishment. Seed Sci. \& Technol, 8, 341-346.

Bulletine, M. S. (1996). Office of Agricultural Commu-nications, Division of Agriculture Forestry and Veterinary Medicine, Mississippi Agricultural \& Forestry Experiment Station. Mississippi State.

Das, G., \& Sen-Mandi, S. (1992). Triphenyltetrazolium chloride staining pattern of differentially aged wheat seed embryos. Seed Science and Technology, 20,367-373.

Dougherty, P. M., \& Duryea, M. L. (Eds.) (1991). Re generation Planning/Forest Regeneration Manual. Kluwer AcademicPublishers, Netherlands.

Hewsten, L. J. (1964). Effect of seed size on crop performance. Rep. Natn, veg Res. Sat., Wellesbourne, 45-46.

International Seed Testing Association. (1995). Handbook of Vigour Test Methods.

Jovall, A., \& Mahgoub (1994). Seed Laboratory Manual National Tree Seed Center. Sudan.

Matthews, S. (1985). Physiology of seed ageing. Outlook on Agriculture, 14. https://doi.org/10.1177/003072708501400206

Mc Daniel, R. G. (1969). Relationship of seeds weight, seedlings vigour and mitochondrial metabolism in Barley. Crop Sci., 9, 823-827. https://doi.org/10.2135/cropsci1969.0011183X000900060048x

McDonald, M. B. (1999). Seed deterioration: Physiology, repair and assessment. Seed Sci. \& Technol, 27, 177237.

Nasr, S., Savadkoohf, S., \& Ahmadi, E. (2013). Effect of differentseed treatments on dormancy breaking and germination in threespecies in arid and semi-arid lands. Sci. Pract., 15(2), 130-136. https://doi.org/10.1007/s11632-013-0209-7

New, T. R. (1984). A biology of Acacias. Oxford, Oxford University Press.

Ovchrov, K. E. (1969). The Physiology of Different Quality Seeds. Proc. Int. Seed test Ass, 34, 305-313.

Perry, D. A. (1980). Avigour test for seeds of barley (Hordeumvulgare) based onmeasurement of plumule growth.

Rehman, S., Loescher, R. N. J., \& Harris, P. J. C. (1999). Dormancy breaking and germination of Acacia salicina Lindl. Seeds. Seed Sci. Techn., 27, 553-557. 
Roberts, H. A., \& Chancellor, R. J. (1979). Periodicity of seedling emergence and achenesurvival in some species of Carduus, Cirsium and Onopordum.

Taylor, A. G., Lee, S. S., Beresniewicz, M. M., \& Paine, D. H. (1995). Amino acid leakage from aged vegetable Seeds. Seed Sci. \& Technol, 23, 113-122. Technology, Thailand.

Tomer, R. P. S., \& Maguire, J. D. (1990). Seed vigour studies in wheat. Seed Sci. Tech., 18, 383-392.

Willan, R. L. (1985). Aguide to forest seed handling special reference to tropics. F.A.O.

Zubairu, S. U. (2014). The Influence of Seed Pre-Treatments on Seed Germination and Seedling Vigour in Acacia senegalin the Nurs. Journal of Biology, Agriculture.

\section{Copyrights}

Copyright for this article is retained by the author(s), with first publication rights granted to the journal.

This is an open-access article distributed under the terms and conditions of the Creative Commons Attribution license (http://creativecommons.org/licenses/by/4.0/). 